\title{
Identification of aluminium dioxalate in fungal cultures grown on vermiculite
}

\author{
Mark S Butler ${ }^{1}$, Kanagasundaram Yoganathan, Antony D Buss and Siewbee Ng \\ The Journal of Antibiotics (2012) 65, 275-276; doi:10.1038/ja.2012.15; published online 14 March 2012
}

Keywords: aluminium; dereplication; oxalate; oxalic acid; solid fermentation; vermiculite

Natural products, especially those derived from microorganisms, have had a very important role in human health through the development of new pharmaceutical drugs, crop protection agents, traditional herbal medicines and personal-care products. ${ }^{1-5}$ In order to identify novel natural products, microorganisms continue to be cultured using different growth media to maximise the diversity of secondary metabolite production. In addition to liquid media fermentations, fungi are also grown in solid media, which can mimic the way these organisms grow in nature. One of the solid media used in our fungal fermentations was vermiculite, which is a clay material mined from various locations around the world. ${ }^{6}$ Vermiculite is an ideal solid substrate because of its high surface area and ability to absorb water, although maintaining a medium shrink-swell capacity. Fungal fermentations grown on vermiculite media were extracted with $\mathrm{MeOH}$ to provide extract libraries that were suitable for high throughput screening (HTS).

One of the targets selected for screening was the Mycobacterium tuberculosis-derived enzyme isocitrate lyase (ICL), with isoforms ICL1 and ICL2 being shown to be essential for in vivo growth and virulence. ${ }^{7}$ ICLs are the key enzymes used by bacteria, fungi and plants $^{8}$ in the glyoxylate cycle that catalyses the cleavage of isocitrate to succinate and glyoxylate. We screened 76466 extracts using a coupled enzyme assay and identified a series of active samples from the vermiculite-based extracts. Active extracts were then subjected to a dereplication procedure; approximately, $1 \mathrm{mg}$ of the crude extract was separated by C18-reversed phase HPLC and collected into 40 fractions in a 96-well microtitre plate. The fractions were dried by centrifugal evaporation and dissolved in $12.5 \% \mathrm{DMSO} / \mathrm{H}_{2} \mathrm{O}$. Biological testing using the ICL screen revealed that the activity of most of the extracts eluted from the column with the water solvent front.

Separation of a crude extract using preparative C18-reversed phase HPLC gave an active fraction ( $\mathrm{IC}_{50} 70 \mu \mathrm{M}$ against ICL) that showed no signals in a ${ }^{1} \mathrm{H}$ NMR spectrum recorded in $\mathrm{D}_{2} \mathrm{O}$, but displayed a prominent mass ion peak at $\mathrm{m} / \mathrm{z} 202.9418$ in the (-)-ESI-TOF-MS, which indicated a molecular formula of $\mathrm{C}_{4} \mathrm{O}_{8} \mathrm{Al}$. The molecular formula was suggestive of aluminium dioxalate, and further evidence

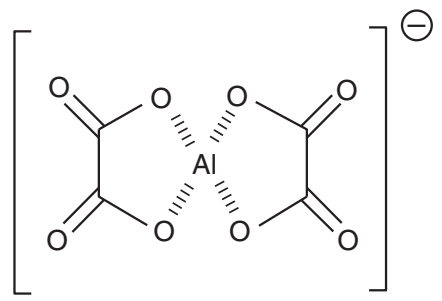

Figure 1 Structure of aluminium dioxalate.

for the compound was obtained by the observation of a single resonance in a ${ }^{13} \mathrm{C} \mathrm{NMR}$ spectrum at $165.3 \mathrm{ppm}\left(500 \mathrm{MHz}, \mathrm{D}_{2} \mathrm{O}\right.$ externally referenced to methanol, lit. ${ }^{9}$ 164.4 p.p.m.). Aluminium trioxalate may be produced in these fungal solid phase cultures but the dioxalate are more easily detected by negative ion ESI-TOF-MS. Aluminium dioxalate (Figure 1) formed by mixing $\mathrm{AlCl}_{3}$ with oxalic acid in $\mathrm{H}_{2} \mathrm{O}$ had identical (-)-ESI-TOF-MS data and was also active in the ICL screen. Oxalic acid has been reported to be active in a Candida albicans ICL screen $\left(\mathrm{IC}_{50} 95 \mu \mathrm{m}\right) .{ }^{10}$ Aluminium dioxalate was also identified as being responsible for the activity of samples in a variety of other biological screens.

Oxalic acid has been shown to be produced by a variety of fungi where it has a role in lignocellulose degradation by wood-rotting basidiomycetes. ${ }^{11,12}$ Aluminium dioxalate has been proposed to have a role in a detoxifying mechanism used by some plants to complex free aluminium, which is toxic to most plants. ${ }^{9,13}$ The metabolic response of Pseudomonas fluorescens to aluminium toxicity has also been reported to involve pathways associated with ICL. ${ }^{14}$ The aluminium that is complexed with oxalic acid is likely to be derived from the vermiculite used in the solid media. This discovery suggests that it is possible to detect oxalic acid as its aluminium salt by (-)-ESI-MS because of the unique mass due to the presence of $\mathrm{Al}$ and high MS sensitivity due to aluminium dioxalate already being negatively charged. This method could be used as a dereplication tool for screens sensitive to oxalic acid. 
1 Newman, D. J. \& Cragg, G. M. Natural products as sources of new drugs over the last 25 years. J. Nat. Prod. 70, 461-477 (2007).

2 Butler, M. S. Natural products to drugs: natural product derived compounds in clinical trials. Nat. Prod. Rep. 25, 475-516 (2008).

3 Dayan, F. E., Cantrell, C. L. \& Duke, S. O. Natural products in crop protection. Bioorg. Med. Chem. 17, 4022-4034 (2009).

4 Gertsch, J. Botanical drugs, synergy, and network pharmacology: forth and back to intelligent mixtures. Planta Med. 77, 1086-1098 (2011).

5 Antignac, E., Nohynek, G. J., Re, T., Clouzeau, J. \& Toutain, H. Safety of botanical ingredients in personal care products/cosmetics. Food Chem. Toxicol. 49, 324-341 (2011).

6 The Vermiculite Association. 〈http://www.vermiculite.net/>, accessed 2 December (2011)

7 Muñoz-Elías, E. J. \& McKinney, J. D. Mycobacterium tuberculosis isocitrate lyases and 2 are jointly required for in vivo growth and virulence. Nat. Med. 11, 638-644 (2005).
8 Dunn, M. F., Ramírez-Trujillo, J. A. \& Hernández-Lucas, I. Major roles of isocitrate lyase and malate synthase in bacterial and fungal pathogenesis. Microbiology 155 3166-3175 (2009).

9 Ma, J. F., Hiradate, S. \& Matsumoto, H. High aluminum resistance in buckwheat: II. Oxalic acid detoxifies aluminum internally. Plant Physiol. 117, 753-759, 1998).

10 Shin, D.-S., Kim., S., Yang, H.-C. \& Oh, K.-B. Cloning and expression of isocitrate lyase, a key enzyme of the glyoxylate cycle, of Candida albicans for development of antifungal drugs. J. Microbiol. Biotechnol. 15, 652-655 (2005).

11 Dutton, M. V. \& Evans, C. S. Oxalate production by fungi: its role in pathogenicity and ecology in the soil environment. Can. J. Microbiol. 42, 881-895 (1996).

12 Currie, J. N. \& Thom, C. An oxalic acid producing Penicillium. J. Biol. Chem. 22 287-293 (1915).

$13 \mathrm{Ma}, \mathrm{J}$. F. Role of organic acids in detoxification of aluminum in higher plants. Plant Cell. Physiol. 41, 383-390 (2000).

14 Lemire, J., Mailloux, R., Auger, C., Whalen, D. \& Appanna, V. D. Pseudomonas fluorescens orchestrates a fine metabolic-balancing act to counter aluminium toxicity. Environ. Microbiol. 12, 1384-1390 (2010). 